\title{
Chapter 18 \\ Urban Energy Systems: Research at Oak Ridge National Laboratory
}

\author{
Budhendra Bhaduri, Ryan McManamay, Olufemi Omitaomu, Jibo Sanyal, \\ and Amy Rose
}

\begin{abstract}
In the coming decades, our planet will witness unprecedented urban population growth in both established and emerging communities. The development and maintenance of urban infrastructures are highly energy-intensive. Urban areas are dictated by complex intersections among physical, engineered, and human dimensions that have significant implications for traffic congestion, emissions, and energy usage. In this chapter, we highlight recent research and development efforts at Oak Ridge National Laboratory (ORNL), the largest multipurpose science laboratory within the U.S. Department of Energy's (DOE) national laboratory system, that characterizes the interactions between the human dynamics and critical infrastructures in conjunction with the integration of four distinct components: data, critical infrastructure models, and scalable computation and visualization, all within the context of physical and social systems. Discussions focus on four key topical themes: population and land use, sustainable mobility, the energy-water nexus, and urban resiliency, that are mutually aligned with DOE's mission and ORNL's signature science and technology capabilities. Using scalable computing, data visualization, and unique datasets from a variety of sources, the institute fosters innovative interdisciplinary research that integrates ORNL expertise in critical infrastructures including energy, water, transportation, and cyber, and their interactions with the human population.
\end{abstract}

\subsection{Introduction}

The Earth is urbanizing rapidly, experiencing an unprecedented rate of population growth that is increasing demand for energy, food, water, and other natural resources, and raising concern about environmental impacts and matters of human security such as poverty, crime, and pandemics. Urban areas account for $67-76 \%$ of global final

B. Bhaduri $(\varangle) \cdot$ R. McManamay · O. Omitaomu · J. Sanyal · A. Rose

Oak Ridge National Laboratory, Oak Ridge, USA

e-mail: bhaduribl@ornl.gov

R. McManamay

Baylor University, Waco, USA 
energy consumption, and 71-76\% of fossil-fuel-related $\mathrm{CO}_{2}$ emissions (Seto et al. 2014). Increases in urban energy use have mirrored the growing global population, increasing urbanization promoted by the migration of population from rural to urban areas for a better quality of life, and rapid evolution of housing, transportation, food, and water, and other associated infrastructures necessary to support urban lifestyle. According to a recent estimate by the World Health Organization (WHO 2019), the urban population in 2014 accounted for $54 \%$ of the total global population, up from $34 \%$ in 1960 . Following this trend, it is widely anticipated that over $70 \%$ of the world's nine billion population will live in urban areas by 2050 . Also, by 2050 , there will be a nearly $50 \%$ increase, compared to 2018 , in the consumption of energy, water, transportation, healthcare, urban infrastructure, and food (U.S. EIA 2019). Most of this growth comes from countries where strong economic growth is driving demand, particularly in Asia. While generation and consumption of electricity dominate urban energy use, it is a combined effect of the growing population and per capita electricity consumption which is higher for developed countries.

Urban areas are characterized by the complex interactions between the critical infrastructure components, such as buildings, utility networks, and mobility systems, and their users at multiple spatial and temporal scales. There are tremendous opportunities to design optimal, resilient urban systems by exploiting the inherent complexity of these interactions; for example, assessment of the impact of new technologies changing the dynamics between energy end-users and distribution and storage systems. Our ability to observe and measure through direct instrumentation of our environment and infrastructures from buildings to the planet scale, coupled with the explosion of data from citizen sensors, provides a unique opportunity to manage and increase efficiencies of existing built environments as well as design a more sustainable future. We can take advantage of both the enormous amounts of spatial and non-spatial data, in traditional and non-traditional forms, as well as new approaches in data science, particularly in geospatial applications, to answer questions for which data had previously not available.

With its mission to deliver scientific discoveries and technical breakthroughs that accelerate the development and deployment of solutions in clean energy and global security, coupled with leadership-class data and high-performance computing infrastructures, the Urban Dynamics Institute (UDI) at ORNL was established in 2014 to develop novel science and technology to observe, measure, analyze, and model urban dynamics from the city to the global scale. UDI's research themes focus on key urban energy issues that drive energy demand, consumption, and efficiency, and efforts to address questions such as: How does distribution and morphology of human settlements and associated population influence energy usage? How do we design mobility systems that make urban transportation energy efficient? How does water use for urban energy production impact our ecological systems? How do we design urban infrastructures that enable cities to reduce energy and environmental costs? To illustrate some of ORNL's contributions to the understanding of such complex urban systems, the following sections are organized into four key themes that reflect the primary dynamics of urban energy systems and have the potential for data-driven analysis: 
1. Population and land use: Provide insights into the evolving spatial and sociodemographic patterns of human population distribution and activity that respond to and transform urban landscapes and systems at varying spatial and temporal scales.

2. Sustainable mobility: Improve transportation sustainability, safety, and accessibility through enhanced understanding of the energy and environmental implications of emerging transportation systems and their interdependencies with other critical infrastructures.

3. Energy-water nexus: Maximize the efficiency, sustainability, and resiliency of interconnected energy and water systems in the planning, development, and operation of urban infrastructures.

4. Urban resiliency: Enhance understanding of the physical and cyber-risks, challenges, and opportunities of the integrated framework of population, energy, water, transportation, and policy to improve reliability and resiliency of infrastructure services under changing and extreme climate conditions.

\subsection{Population and Land Use}

One of the biggest challenges in urban energy applications is the lack of data for population and land use that would be required to adequately investigate urban issues, particularly those tied to energy access and use. Further, even when data are available, the resolution of the analyses we would like to conduct is often much finer than the data available in support. In this section, recent innovative approaches developed at the UDI are discussed that address existing data gaps so that energy access and consumption patterns may be better modeled and evaluated both locally and globally.

\subsubsection{Big Data and GeoAI to Create Population and Land-Use Data}

Urban areas continue to grow both in expanse and magnitude of population, which heightens the need for increasing environmental awareness. Population distribution and dynamics data are foundational to assessing energy demand and usage patterns, which in turn guide energy generation and distribution scenarios. For the past two decades, ORNL has provided the community with LandScan Global fineresolution $(1 \mathrm{~km})$ population distribution data for the world utilizing global-scale remotely sensed data through a smart interpolation technique (Bhaduri et al. 2002). This approach was further extended to LandScan USA, a $90 \mathrm{~m}$ population distribution and dynamics dataset for the USA, that used over sixty different geographic datasets to create both nighttime residential and daytime population (Bhaduri et al. 2007). Recently, Weber et al. (2018) have demonstrated a further refinement of this 
smart interpolation approach for census-poor regions by developing $90 \mathrm{~m}$ population distribution estimates for Nigeria, where human-settlement data from fineresolution satellite images, categorization of settlements in different land-use classes, and population-density appraisals from census-independent sources were employed.

Understanding the existing structures of cities and their futures is an important component of urban sustainability and resiliency, particularly for assessing present and future energy usage. Up-to-date and highly resolved land-use maps allow researchers, policymakers, and other stakeholders to inform the better allocation of resources to communities. However, accurate and complete land-use data remain scarce for most of the developing world. Even in the developed world, this information is often geographically disjointed and incomplete. An important step in addressing this need is to develop robust, scalable, and automated methods to differentiate development patterns in fine-resolution satellite imagery by semantic segmentation. A recent collection of work by ORNL researchers (Arndt et al. 2019; Kurte et al. 2019; Lunga et al. 2018; Yang et al. 2018) have tackled various challenges associated with developing machine-learning models for urban-feature characterization and extraction. CNN-based deep-learning methods were used for automated land-use classification and to develop a typology for urban land-use data that captures the variation in structural patterns within cities. These development patterns, or more generally land use, can be used to spatialize variables within cities. These variables can include socioeconomic indicators such as electricity consumption patterns, as discussed later in this section, which are traditionally difficult to capture. Given that land use is shaped by human activities, researchers have utilized cellular phone-call data records (CDR) to infer land use. Using tower-based call data from Dakar, Mao et al. (2017) analyzed aggregated call volume and applied non-negative matrix factorization to identify fundamental behavioral classes of human activity patterns, and successfully inferred two fundamental land-use patterns: commercial/business/industrial (C/B/I) and residential (Fig. 18.1).

Evaluating energy consumption patterns, particularly in conjunction with highly resolved maps of settlement types, can be a useful first step in identifying areas that lack access to energy and other urban services. Many of these areas are considered slums, housing nearly 1 billion people worldwide (UN Habitat 2016). On a global scale, locating and monitoring the magnitude and composition of these areas is critical for making progress toward improving the lives of those who live there. This goal is the focus of the Millennium Development Goal 7 Target 7D (http://www.un. org/millenniumgoals/), "to have achieved by 2020 a significant improvement in the lives of at least 100 million slum dwellers", as well as a proposed measure of the Sustainable Development Goal 11 Target 11.1 (https://sustainabledevelopment.un. org/), "By 2030, ensure access for all to adequate, safe and affordable housing and basic services and upgrade slums".

Recent work by Brelsford et al. (2018; and see https://www.youtube.com/watch? $\mathrm{v}=$ YuRjeUkNf9o) shows how maps of these areas can be put into action. Once slums are identified, this study shows how we can address the problem of accessibility in these neighborhoods using topological analysis. Ultimately, the study revealed that urban slums showed a different topological structure than that of developed 


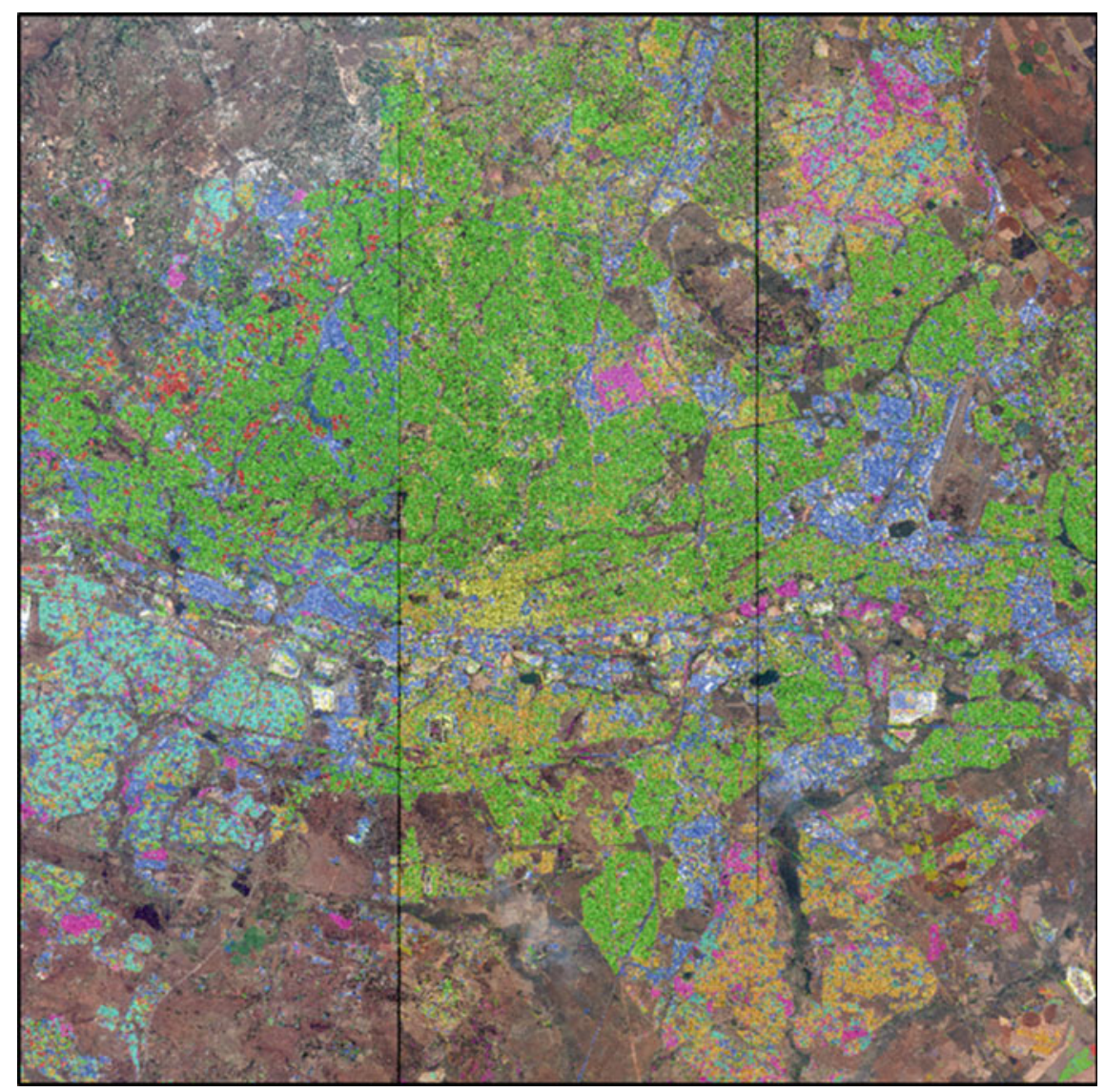

Fig. 18.1 Different land use in Johannesburg, South Africa, delineated from deep learning on fine-resolution satellite imagery. Various residential areas are shown based on different levels of formality of structures

cities - a critical piece of information to address the problem of accessibility to services. This work investigates the potential to increase that accessibility in these areas with minimal cost by growing road networks in existing slums and demonstrates its effectiveness through examples in Mumbai, India; Cape Town, South Africa; and Harare, Zimbabwe. 


\subsubsection{Estimating Urban Electricity Use in Data-Poor Regions}

In many parts of the world, sustainable and universal energy access is a persistent challenge. This is particularly problematic considering that urban areas, which are the most rapidly growing areas of population, presently consume around threequarters of the global energy supply. Understanding these urban-energy consumption patterns would be a strong first step toward addressing challenges as related to urban sustainability and energy security. Yet the required urban-energy datasets are virtually non-existent for the developing countries where this information is most critical. This creates an urgent need to develop new research methods for capturing and quantifying urban-energy use patterns. Without available urban-level energy statistics, capacity building and accessibility planning and assurance become prohibitive, particularly in data-poor regions of the world where future urban growth is expected to be the largest.

In a recent study conducted by Roy Chowdhury et al. (2020), a data-driven approach to characterize urban settlements based on their formality was conducted to assess intra-urban-energy consumption in three cities. Since electricity is the fastestgrowing energy fuel, the premise of the study is to evaluate the relationship between urban settlement types and corresponding nighttime light emission, which is considered a proxy of electricity consumption. This study presents an approachable and scalable solution to fill the existing data gap to better understand differential electricity consumption patterns.

Three cities in the developing world-Ndola, Zambia; Sana'a, Yemen; and Johannesburg, South Africa-were used in this study as they collectively displayed considerable variation in population size and socioeconomic characteristics. These variations were useful in order to examine which characteristics may result in distinct electricity consumption profiles. Following an approach developed by Yuan et al. (2015), human settlement areas within these cities were classified into different functional types. Those distinct settlement types were then correlated with nighttime lights emission from VIIRS DNB (https://earthdata.nasa.gov/viirs-dnb) data following the assumption that lights are a reasonable socioeconomic indicator and can help us to understand electricity consumption. In all three study cities, a statistically significant correlation between human settlement types and nighttime lights emission (considered as a surrogate of electricity consumption) was discovered, which demonstrates the potential to develop and generalize this method to other geographic areas in order to understand energy consumption patterns within cities, specifically when no other data are available.

The data-driven approach captured in this study not only mitigates issues where no ground information is available, but the patterns of energy consumption that are uncovered can be used in myriad analyses, particularly when combined with other information such as land-use maps, to inform urban planning where energy resources may be limited (Fig. 18.2). 



Legend

VIIRS DNB

Settlement Classes


Fig. 18.2 Clockwise from top-left: Settlement map, settlement classes, settlement classes overlaid on VIIRS DNB image, and VIIRS (from Roy Chowdhury et al. 2020) 


\subsubsection{Estimating Household-Level Energy Consumption}

Understanding residential energy consumption patterns is of critical importance since this sector alone accounts for nearly $30 \%$ of all energy consumption worldwide (IEA 2016). One limitation of current approaches to model energy consumption is that they are highly dependent on region-specific data sources requiring building-level detail, which are generally not openly available. Surveys that capture population and housing characteristics are commonly conducted for small segments of the population and provide household-level or individual-level samples from a single neighborhood, city, region, or country to provide very detailed information. Although these data contain considerable sociodemographic depth, they are not available for a full population. To address this disparity, synthetic spatial microdata-a high-performance, data-driven simulation of the American population-for modeling urban dynamics, termed UrbanPop, were developed at ORNL to simulate the American population with fine-resolution human demographics (e.g., Census block/block group) that match aggregate census data at the block, block group, and tract. In other words, given a set of demographic attributes of interest, the algorithm can recreate joint distributions of these attributes at the block or block-group level that when aggregated, return the census results within a certain margin of error. The algorithms in UrbanPop consider the full demographic profile of commuters and trace the movements of the profile from the nighttime (home) and daytime (work).

In a recent study by Morton et al. (2017a, b), a fine-resolution residential electricity consumption model was developed by merging a dasymetric model with a complementary machine-learning algorithm. The foundation of this approach is the use of publicly available data, supporting a model that is applicable to a wide range of regions. The authors used UrbanPop data to estimate residential energy consumption, combined with the 2008-2012 household-level Public Use Microdata Sample (PUMS; https://www.census.gov/programs-surveys/acs/data/pums.html) of the American Community Survey (ACS), to provide detailed demographic and household characteristics, as well as the average monthly electricity cost per household. The 2008-2012 ACS summary tables, which contain both tract- and block-grouplevel average totals, were used as constraints. The model was tested on three counties in Tennessee (Anderson, Knox, and Union) by using a dasymetric approach to disaggregate a weighted sample of surveyed households into smaller geographic areas and then using a learning algorithm to estimate electricity consumption for each of the households. These estimated values at the household-level were then aggregated to larger areas for analysis.

This approach demonstrated its utility by estimating and evaluating aggregate block-group-level residential consumption within a growing urban area. Further, it also provides a well-defined method for handling the uncertainty that enters into the model via input data sources. The ability to estimate the residential energy consumption while still capturing measures of uncertainty provides analysts with an improved set of data to evaluate spatio-demographic factors that may impact energy use. This deeper understanding can then translate into the implementation of 
effective energy-efficiency measures, particularly in urban areas that are experiencing rapid growth.

This study illustrates a practical path forward for estimating highly resolved energy consumption patterns while overcoming data limitations through the use of openly available data. Although this specific study does not include a formal validation process, both internal and external validations have been conducted on the algorithm used here (Rose and Nagle 2017).

\subsection{Sustainable Mobility}

In 2018, vehicles moved an estimated 11 billion tons of freight, more than $\$ 32$ billion of goods per day, and traveled 3 trillion vehicle miles in the USA according to the U.S. Department of Energy's Vehicle Technologies Office. Transportation typically accounts for about a third of all energy used in the nation, and developing sustainable transportation solutions is imperative as the nation's economy expands and the global economy grows. In recent years, the word mobility is increasingly used to refer to various aspects of human interactions with transportation systems. Mobility encompasses the notion of being inclusive of multi-modal transportation options, smart connectivity, crowdsourced data-enabled transportation alternatives, ride-hailing and ride-sharing options, as well as system-scale efficiencies for transportation system design. Clearly, developing sustainable means of mobility has societal, economic, as well as environmental benefits (Bigazzi and Bertini 2009). Recent advances in ubiquitous sensing, big data, social media platforms, and the growth of app-based mobility options has heralded an unprecedented shift in not just mobility but also vehicle ownership. Increasingly, people are considering not owning vehicles and accessing their mobility needs as a provided service.

Significant changes are also here from an infrastructural standpoint. The variety and types of deployed sensors on and about roadways have gone up. Typically, cities these days have a number of fine-resolution cameras deployed with real-time video feeds, radar detector sensors every few hundred yards recording speed and volume every couple of seconds, induction loops coupled with spherical cameras detecting stationary queues and turning vehicles, control algorithms to coordinate signals, as well as Bluetooth sensors to detect flows through urban environments. Coupled with advances in connected and automated vehicles, opportunities are ripe for data-driven system-wide approaches for control and optimization.

\subsubsection{Human Interactions with Transportation Systems}

In complex urban environments, population, transportation, building energy, and urban climate are interdependent. The modeling of each individual component is 
fairly mature; however, the modeling and simulation of complex urban interactions pose significant challenges. By coupling the individual systems, one moves from studying different aspects in isolation toward studying a city as a whole. Active transportation can be defined as any self-propelled, human-powered mode of transportation, such as walking or bicycling that is often mixed with public transportation and helps to alleviate congestion, reduce energy consumption and greenhouse gas emissions, and fight against chronic health conditions such as obesity, diabetes, heart disease, and stroke. Promoting active transportation modes requires analysis of factors that substantially influence a transportation mode-choice process. Each transportation mode has a unique set of influencing factors for individuals, including sociodemographic attributes, transportation cost and network characteristics, and social interactions. This emphasizes the need to understand macro aspects of transportation-mode choices by modeling millions (or even billions) of commuters and their complex, simultaneous, and mutually dependent decision processes. Agentbased modeling and simulation (ABM) approaches offer a mechanism to represent such a complex system as a collection of autonomous agents and their environments, in which the agents interact with one another and with their environments.

Recent research by Aziz et al. (2018a, b) and Park et al. (2018), explored the effects of traffic safety, walk-bike network facilities, and land-use attributes on walk and bicycle mode-choice decision in New York City for the home-to-work commute. Applying the flexible econometric structure of random parameter models, they captured the heterogeneity in the decision-making process and simulated scenarios considering the improvements in the walk-bike infrastructure such as sidewalk width and length of bike lanes. They utilized fine-resolution sociodemographic data from UrbanPop to estimate likely night and day locations for individuals matching a demographic profile, and suggested appropriate origins and destinations (OD pairs) for synthetic commuters. The determination of OD pairs is a fundamental input for transportation and mobility applications. Using the UrbanPop simulated population, an agent-based model was implemented on ORNL's Titan supercomputer (Park et al. 2018) to simulate mode choices for commuters in New York City, and how these mode choices might be tipped in favor of bike or walking (Park et al. 2018; Morton et al. 2017a, b). Creating agent-based models from the simulator allows the exploration of how improvements in sidewalk conditions or having bike lanes may impact commuter choices to bike or walk instead of driving or using public transit. The results from the New York City case study indicate that infrastructure investments such as widening sidewalks and increasing bike lane networks can positively influence active transportation mode choices (Fig. 18.3). The impact varies with geographic locations. The ABM simulation results indicate that social promotions focusing on active transportation can positively reinforce the impacts of infrastructure changes. 


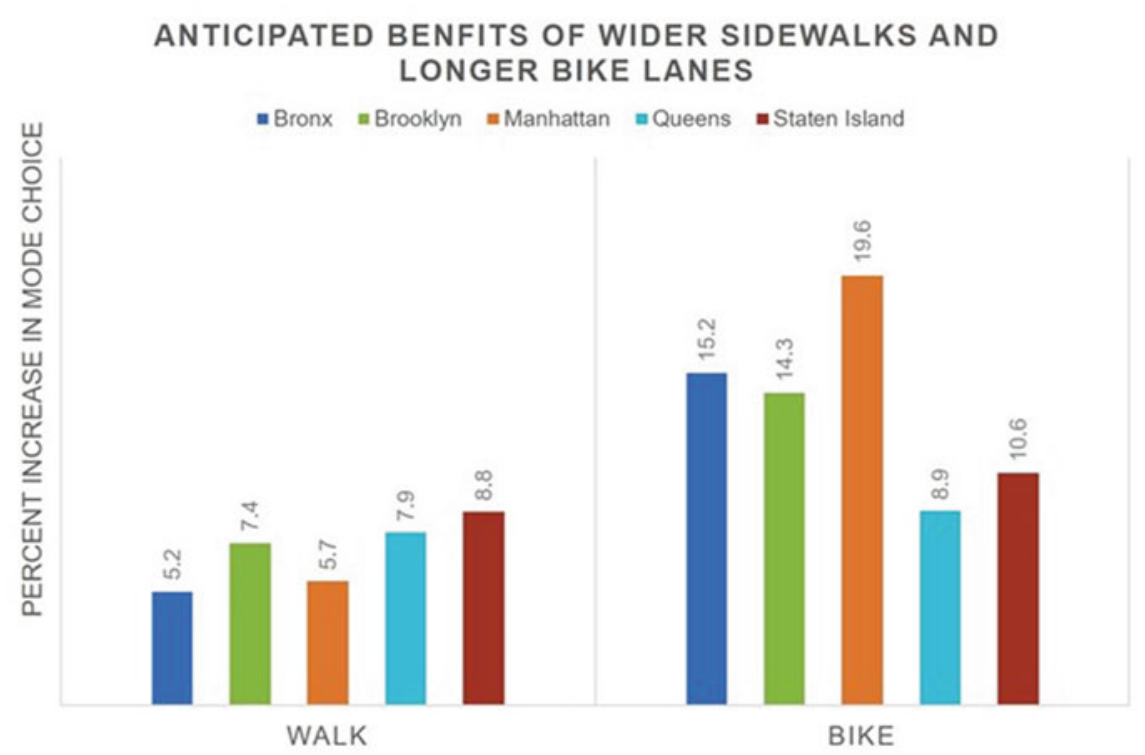

Fig. 18.3 Effect of wider sidewalk and building more bike lanes in the five boroughs of New York City

\subsubsection{Emerging Options for Freight Delivery for Businesses}

Freight, and particularly intra-city freight delivery, is a key aspect of the course of business activity that depends on mobility. Due to the relatively recent shift in consumer preferences to purchase items online rather than making purchases in brick-and-mortar stores, and the preference for next-day and same-day delivery, logisticians and parcel delivery companies have been prompted to search for new ways to move and deliver parcels to improve efficiency and reduce costs associated with energy usage. ORNL conducted a study to consider innovative modes of parcel delivery, and modal configurations involving multiple modes of freight transport, with a focus on the last mile (Moore 2019). The data for this study consisted of GPS traces of delivery-truck tours from a portion of the truck fleet at the UPS depot outside of Columbus, Ohio. Delivery locations were extracted from the dataset and used along with socioeconomic and land-use data obtained from the metropolitan planning organization for Columbus, to develop a delivery-demand model to estimate parcel deliveries in areas lacking GPS data.

Alternative scenarios were developed involving the use of electric Class-Six trucks, electric delivery vans, parcel delivery lockers, the use of drones, as well as electric passenger vehicles. Energy usage in kilowatt-hour per mile was estimated for the scenarios and compared with energy estimates for the baseline case involving the standard Class-Six delivery truck. The findings suggest that electric Class-Six 
delivery trucks paired with parcel delivery lockers reduce energy usage, especially in suburban neighborhoods. The findings also suggest the use of parcel lockers in suburban areas, which typically have less connectivity and more cul-de-sacs. Pairing both electric Class-Six delivery trucks with parcel lockers significantly reduced energy usage in outlying TAZs (traffic analysis zones) in suburban Columbus. The scenarios involving drones, on the other hand, were found to be energy-intensive, and suggest the need for more optimized drone scenarios which consider improved drone technology, such as increased battery range and payload, and more efficient use of the technology, possibly including the use of multiple drones, mid-air transfers, and improved flightpaths.

\subsection{Energy-Water Nexus}

To date, there is no widely accepted and consistent definition of the energywater nexus, although the EWN is broadly conceptualized as the interdependencies between the energy and water, such as the water required to produce electricity, or the amount of electricity required to treat and distribute water. However, when applied to urban dynamics and informatics, defining the EWN becomes even more obscure. For instance, in the context of urban systems, the need to expand the EWN to consider linkages and dependencies among other sectors, such as agricultural development and natural and human-built environments, becomes quite apparent. Planning for urban growth or infrastructure expansions requires understanding complex relationships and feedbacks among multiple sectors, and the potential consequences of population growth and climate extremes on infrastructure resilience, operations, and resource availability and stress. Characterizing these relationships requires consideration of appropriate scales and overcoming challenges to data and analytical limitations. In this section, we expand upon research within the Urban Dynamics Institute that has used informatic-type approaches to explore the urban EWN through consideration of scale and removing obstacles to data challenges. First, however, we discuss the importance of scale, and data and analytical challenges, to linking the EWN to urban informatics.

Scale considerations As with all research that examines the hierarchical complexity of systems, the difficulty of developing a consistent working definition of the EWN is a matter of scale (Allen and Star 2017). For example, the broadest definition of the EWN includes research spanning multiple spatial and temporal scales, from developing efficient membrane technologies for desalination (micro-scale) to agent-based modeling of electricity and water use by water treatment systems (meso-scale), to the development of plausible socioeconomic scenarios of future global communities (macro-scale). In this respect, a focus on urban dynamics actually helps to constrain the scope of the EWN in the following ways. First, an urban focus imposes a requirement of scales that examine collective behaviors of more than one human, who might move substantial distances within short periods of time and utilize a range of resources that impact many sectors that are internal 
and external to urban boundaries. Second, dynamics suggests a need to understand the behavior of systems, which are composed of multiple interacting parts. Finally, a central construct for the ORNL Urban Dynamics Institute is that almost all research has a spatial or mappable component. Hence, when we apply these constraints to the field of multi-sector research, the scales would indeed be restricted to consider spatial units no smaller than neighborhood levels (possibly buildings), whereas the temporal scales remain unrestricted.

Challenges Accurately depicting and characterizing multi-sector relationships and interdependencies comes with many challenges, primarily related to data. These include limited data availability for both energy and water infrastructures and use, mismatches in spatial and temporal scales of data across different sectors, heterogeneity in data types, and lack of standards for data collection and availability (US DOE 2014; Zaidi et al. 2018). For example, Chini and Stillwell (2018) reported that data on urban water resources are highly limited, and data on energy requirements for water treatment and distribution are virtually absent. Obviously, this prohibits the accurate characterization of urban-energy-water dynamics to support infrastructure investments and predict resiliency under climate uncertainty. Even if data are available, practitioners and research communities may be unaware of the wealth of analytical approaches that are available for characterizing urban EWN dynamics (Allen et al. 2018). Possibly more troublesome is how to integrate the disparate modeling platforms that are used to characterize patterns and processes within different sectors (Brewer et al. 2018). Furthermore, the multi-dimensionality and sheer complexity of the EWN, in conjunction with limited data, may constrain which components and relationships are evaluated, leaving major gaps of knowledge in understanding the implications of urban growth for sustainability and resiliency.

EWN interface with Urban Dynamics Institute To address these challenges, ORNL, through support from the DOE Biological and Environmental Research Integrated Assessment Research Program, developed the Energy-Water Nexus Knowledge Discovery Framework (EWN-KDF) (https://climatemodeling.science.ene rgy.gov/projects/energy-water-nexus-knowledge-discovery-framework). The KDF provides a data management and geovisual analytics platform to enable efficient characterization of energy-water relationships and decision making regarding present and future infrastructures (Bhaduri et al. 2018). As stated previously, obstacles to discovering complex relationships within the EWN relate to time expenditures associated with the acquisition and storage of data, but also the fusion of disparate data sources and data types from mismatched spatiotemporal scales. In part, the KDF platform expedites this process by harnessing Argonne National Laboratory's Globus clouddata transfer service, which bypasses the need for the EWN community to download and manipulate data locally. The KDF also provides quick access to widely applicable climate, physical (or physiographic), and socioeconomic datasets. To address the challenge of accelerating knowledge discovery, the KDF provides real-time coupled analytic and visualization capabilities for users to explore anomalies or anomalous behavior in datasets as well as spatiotemporal clustering and trend analysis. As an example, suppose a user desires to understand complex spatial and temporal relationships (or tradeoffs) among land and water use in regions experiencing elevated 
population growth and water stress. A commonly used dataset available through the KDF is the US Geological Survey's Water Use in the United States (USGS 2018), which provides county-level estimates of surface and groundwater use among eight major economic sectors from 1985 to 2015. The KDF also assembled land-cover estimates within counties for the same period of record. To allow users to explore spatiotemporal patterns, the KDF provides dynamic time warping, which uses algorithms to measure the similarity between temporal sequences, such as water-use and land-cover changes over time. Similarity matrices are seamlessly incorporated into clustering algorithms to explore regions or counties that share similarities in temporal signatures or behaviors. These analytics and visualizations are rendered in real time, allowing users to quickly explore and understand dynamic patterns; it would take hours, if not days, to conduct analogous exploration on local machines. By increasing the rate at which users can observe new phenomena, the KDF creates a robust learning platform that changes the rate and nature of hypothesis generation for urban EWN dynamics.

Another application of EWN to urban dynamics is through examining dependencies between cities and their neighboring regions. To support the resource demands of dense populations, cities rely on expansive infrastructure that supplies numerous commodities, such as energy, water, food, and material goods and services (Ruddell et al. 2014). Therefore, city and utility governance must remain cognizant of these external supply chains, as well as how offsetting their resource burdens to outside regions induces stress on natural resources, particularly water availability (McManamay et al. 2017). These increasing stressors are important to quantify, as limited resource availability makes cities more vulnerable to climate extremes. However, a significant challenge to effective decision-making across sectoral boundaries is that of transcending disparate policies and jurisdictions, since each sector is governed by different entities, which operate on different scales and rely on different information. For instance, how does a city planning official translate population growth and land zoning at the parcel scale into estimates of stress on water intake and treatment infrastructures at the stream level (i.e., water policies), or stress to the electricity grid at the power-plant level (i.e., energy policies)? Creating spatially explicit maps of interconnected infrastructures and relationships between demand and regional sources of commodities provides transparency and interpolicy coordination to all parties involved in planning for future urban growth. Of course, for the reasons stated earlier, capturing these relationships is difficult due to limited data availability, heterogeneous data, or mismatched scales.

A couple of recent projects through ORNL's UDI use informatics to overcome these challenges by developing spatially explicit interconnections between cities and their regional infrastructures. One example is the development of city energy sheds, that is, a region outlying an urban center and comprised of the transmission infrastructure and electricity production at powerplants that are required to offset high electricity consumption occurring within urban areas (McManamay et al. 2017; DeRolph et al. 2019; Fig. 18.4). Over 100 US cities have established goals to transition to $100 \%$ renewable energy (Sierra Club 2018); however, detailed strategies for how to make these transitions effective vary immensely across cities. Furthermore, we surmise 


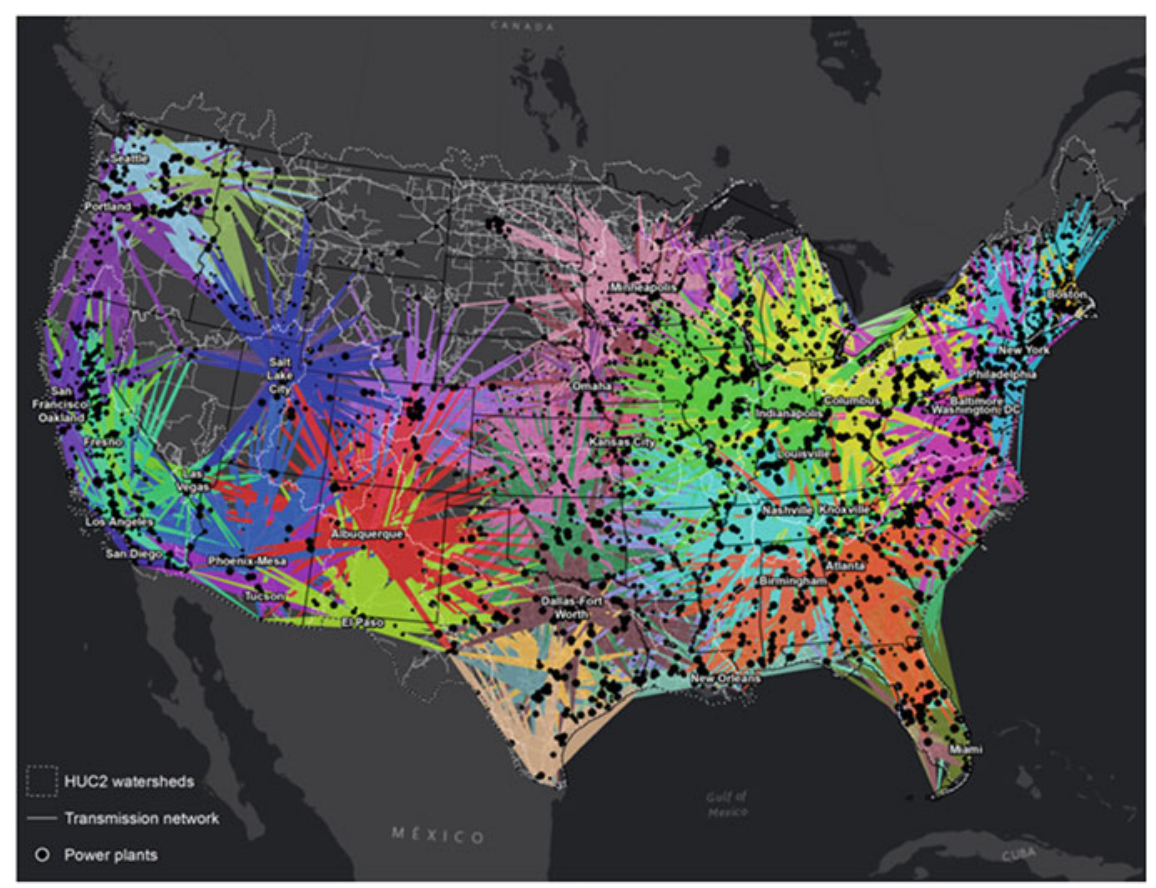

Fig. 18.4 City energy sheds depicting sources of electricity supplying urban epicenters. Taken and modified from DeRolph et al. (2019)

that most city governance and sustainability officials are unaware of the electricity footprint and the magnitude of infrastructural investments required to make these transitions. Using available information on transmission and substation infrastructure and electricity production at powerplants, DeRolph et al. (2019) used a market-share network allocation optimization in ArcMap (Esri, Redlands CA) to balance the electricity grid for the conterminous USA The grid was amended to include connections between substations and census block groups, and annual electricity demand was downscaled from state-level electricity consumption (from the Energy Information Administration). Such an exercise was computation-intensive: The grid considered that any one of the nation's 200,000 block groups could receive electricity from $>5000$ power plants weighted by transmission voltage, which creates over 1 billion unique combinations; however, electrical impedance increased with distance, and lower transmission voltages were used to constrain the optimization. By isolating only block groups within urban boundaries, DeRolph et al. (2019) identified the powerplants providing the majority of a city's electricity demand (Fig. 18.4). Additionally, this provides a template to quantify a city's indirect carbon and water footprints through electricity production. The analysis yielded very important insights: First, the majority of US cities, especially those with aggressive renewable-energy transition plans, have energy mixes that are far from attaining $100 \%$ renewable status. 
Hence, the transition will require massive infrastructure investments. Secondly, those cities facing electricity congestion challenges from immense population growth and electricity demand do not consistently have public support or local and state policies to enable renewable energy transitions to meet growing demands.

Understanding the implications of city growth on regional water availability is also critical. Another UDI project examined the fine-resolution impacts of city land transformation, electricity production, and water supply infrastructure on hydrologic alteration and biodiversity loss in streams (McManamay et al. 2017). Such an analysis requires multiple steps to isolate the individual effects of city infrastructures on aquatic ecosystems experiencing cumulative anthropogenic stress from areas outside the influence of cities. Furthermore, each step has unique information challenges: (1) estimating commercial and residential energy and water demands at fine resolutions, (2) mapping detailed infrastructures required to meet those demands, (3) geospatially summarizing infrastructures in ways meaningful for stream-network analysis, (4) using statistical models to estimate hydrologic alteration, (5) statistically isolating roles of individual sectors in contributing to cumulative hydrologic alteration, and (6) assembling biodiversity occurrence information to estimate species losses due to urban drivers. We highlight a few ways in which informatics approaches provided opportunities to characterize these complex relationships. Landscape alterations induce up-to-downstream impacts on river systems; therefore, predicting how infrastructures may alter hydrology required accumulating geospatial information for dendritic stream networks. Additionally, translating these geospatial variables into measures of hydrologic alteration requires either calibrating mechanistic models (i.e., time consuming) or using novel statistical approaches, which are far less time consuming, but no less accurate. McManamay et al. (2017) summarized geospatial variables in NHDPlus stream reaches (Horizon Systems Corporation 2019) using the network analyst in ArcMap, and then assembled discharge information for streams from the US Geological Survey National Water Information System. After calculating metrics depicting hydrologic departures from natural or reference conditions, the authors then used machine-learning algorithms (random forests) to relate geospatial characterizations of city infrastructures to hydrologic alterations at the streamreach level. Isolating the roles of individual sectors (e.g., electricity production, water supply) on hydrologic conditions in streams becomes very difficult in situations of compounded stress from upstream sources. Hence, McManamay et al. (2017) extracted partial dependency functions (PDFs) from random forests to estimate how individual variables (or combinations of variables) associated with a given sector influence hydrologic conditions. Once sector-specific hydrologic alterations were isolated in streams, millions of occurrences of aquatic species were organized by taxa and conservation concern and then overlain with those areas to characterize the city-aquatic biodiversity nexus.

A remaining challenge of supporting multi-sector decision-making for urban dynamics is creating user-centric Web-visualization and analytic platforms. As a brief example, ORNL developed a stream classification Web application to guide decision-making for stream restoration and mitigation (McManamay and Derolph $2019 a, b)$. Such a tool is highly relevant to urban dynamics, as stream restoration 
in the USA is related to remediating the impacts of urban landscape transformation (Bernhardt et al. 2005, 2007). The premise of the stream classification is guiding users to appropriately select reference streams to guide restoration practice, through the selection of streams that share similar physical typologies (McManamay et al. 2018). The Stream Classification Web-App allows users to query any of the nation's 2.6 million stream reaches and find streams that share similar natural properties or anthropogenic disturbance regimes. Unfortunately, seeking more complex platforms that support urban EWN dynamics induces tradeoffs between flexibility, application breadth, and computational expense. For instance, one strategy might provide highly flexible applications seeking maximum relevance to a wide spectrum of user groups, but possibly only supporting superficial decision making. The opposite endpoint might consist of applications with far less flexibility but substantial depth to support decision making from a narrow user group or a narrow range of applications. This tradeoff becomes critical when designing platforms for EWN relationships to urban dynamics, as finding an optimal balance between flexibility and provision of meaningful outcomes becomes very difficult when considering multiple sectors and their complex (and uncertain relationships). Nonetheless, platforms that achieve this optimal balance are in increasing demand from all sectors of government and the economy.

\subsection{Urban Resiliency}

Urban resiliency indicates how a city recovers better and stronger after a shock. Such a shock could be due to natural or humman-made disasters, failure of engineered infrastructure, economic downturns, and so on. Long-term climatic trends and shortterm extreme weather events (e.g., 2011 earthquake and tsunami in Japan, 2012 Superstorm Sandy in Northeast U.S., 2018 Hurricane Maria in Puerto Rico, 2018 wildfires in Northern California, etc.) have renewed interest in the concept of urban resiliency. The resiliency of urban water and energy infrastructures is of relevance in this context. For example, in the longer term, estimating renewable energy potential, assessing existing renewable energy infrastructures, managing urban flooding with green infrastructures to minimize energy cost for pumping water out of flooded areas, reducing energy usage for snow and ice removal, and water-quality impacts from urban de-icing are of key interest for cities. For near-term disruptions, having a distributed renewable (solar) energy infrastructure builds resiliency when the electric grid is disrupted by disasters; and also developing a situational awareness for the nation's energy infrastructures is critical during the emergency preparedness, response, and recovery phases of natural or technological disasters. Consequently, researchers at ORNL are developing new methods and approaches for building a more resilient urban infrastructure by utilizing scientific and open-source data resources. In this section, three approaches are discussed that focus on one of the most important agendas that decision-makers will be facing in the coming decades-integration of 
resilience thinking into urban planning to improve response to known and unknown risks.

\subsubsection{Renewable Energy-Infrastructure Assessment}

Solar photovoltaic (PV) is the fastest-growing source of distributed generation of renewable energy. In fact, renewable-energy capacity is projected to expand by $50 \%$ between 2019 and 2024, led by solar PV. This increase of $1200 \mathrm{GW}$ is equivalent to the total installed power capacity of the USA today. Estimating solar potential in urban environments, namely on building rooftops utilizing LiDAR-derived 3D elevation models with solar radiation data, has shown to be an effective approach (Nguyen et al. 2012; Latif et al. 2012; Kodysh et al. 2013). However, data for the actual spatiotemporal distribution of installed solar panels greatly benefits applications related to energy policy-making, power systems, and solar PV market analysis but was not available on a large scale till recently (Yu et al. 2018; Hou et al. 2019). Recognizing this data challenge, as early as 2012 ORNL researchers were among the first to develop a machine-learning approach based on a convolutional neural network $(\mathrm{CNN})$ that exploited large-scale, fine-resolution $(0.3 \mathrm{~m})$ aerial imagery to efficiently and accurately detect rooftop-installed solar panels covering large areas in two US cities (Bradbury et al. 2016; Yuan et al. 2016).

\subsubsection{Optimizing Energy and Safety Through Precision De-icing}

In the USA, more than $\$ 1.5$ billion is spent every year for winter road maintenance programs. In addition to these direct costs, each state in the country incurred between $\$ 300$ and $\$ 700$ million per year in indirect costs (Transportation Research Board 1991). As the number and severity of snowfall events grow, the need for safer urban roads during snowfall events is also growing. In 2014, the Pennsylvania Department of Transportation dispensed 686,000 tons of salt for road treatment; that is, 200,000 more tons than was used in the average year (Black and Arking 2014). While overtreating roads with salt and brine has energy, environmental, and financial burdens, undertreatment can lead to decreased safety on the roadways as described in a study that has shown that snow depth correlates with the number of traffic accidents (Seeherman and Liu 2015).

Road-treatment chemicals, such as brine solutions and common road salt, together with plowing, are effective tools for snow and ice removal. However, there are two challenges that impact the resiliency of cities during snowfall events: (1) lack of enough resources to treat all roads in a city, thus limiting social and economic activities in the city; and (2) excessive use of road salt increases urban environmental 
impacts. The first challenge is addressed by preselecting roads to be treated based solely on traffic counts. Thus, streets with high traffic volumes are treated, while feeder streets, trouble spots, and neighborhood roads often go untreated. Consequently, many residents are unable to safely make it to the treated roads, lowering the overall utility gained from the treated roads. With enough resources, all the roads in a city can be treated, thus leading to the second stated challenge.

The impacts of excessive use of road salt are: (i) increase salinity of groundwater and surface water adjacent to roadways, potentially impacting human health and resulting in localized decreases in the biodiversity of organisms; (ii) creation of unfavorable changes in the physical properties of roadside soils leading to increased surface runoff, erosion, and sedimentation of rivers and streams; (iii) increased corrosion rates of automobiles, highway components, steel reinforcement bars, and concrete; (iv) increasing incidence of vehicle-animal accidents-birds and mammals are attracted to road salt; and (v) decreasing health and vigor of roadside plants due to water stress and soil nutrient imbalances (Kelting and Laxson 2010).

In order to make more urban roads safer without using excessive road salt, researchers at ORNL developed a new metric called the Road Vulnerability Index to snowfall accumulation (RVI). The premise of this index is that road segments should be classified based on their capacity to melt snowfall quickly and their elevation value. The behavior of snowmelt in a given situation depends on temperature, precipitation, humidity, wind, and cloudiness (NRCS 2004). The developed methodology divides the urban roads into road segments of $50 \mathrm{~m}$ length as suggested in the literature (e.g., Chapman and Thornes 2011). The rate of snowmelt (RoSM), based on the thermodynamics of snowmelt, is then calculated for each road segment using the U.S. Army Corps of Engineers formulation (USACE 1998) during non-rainy periods and rainy periods. The incident solar radiation data is obtained using the hemispherical viewshed algorithm and LiDAR (Light Detection and Ranging) data (Kodysh et al. 2013). Using the rate of snowmelt and slope data, the road segments are then classified into RVI categories (Chapin et al. 2017) using the classification rules shown in Table 18.1 .

The RoSM data are grouped into five classes based on their solar insolation values. The RVI has four categories: Least Vulnerable (1), Less Vulnerable (2), More Vulnerable (3), and Most Vulnerable (4) as shown in Table 18.1. A map showing the RVI categories for the City of Knoxville, Tennessee is shown in Fig. 18.4. The city has 6555 lane miles, of which 722 miles are classified as Categories 1 and 2 roads, 4916 miles are classified as Category 3 roads, and 917 miles are classified as Category 4 roads. Using the RVI approach, Category 4 roads need more attention and

Table 18.1 Classification rules for RVI categories

\begin{tabular}{l|l|l|l|l|l}
\hline \multirow{2}{*}{ Slope } & \multicolumn{5}{l}{ RoSM } \\
\cline { 2 - 7 } & 1 -Sunny & 2 & 3 & 4 & 5 -Shaded \\
\hline 0 -Flat $(\leq 10 \%$ grade $)$ & 1 & 2 & 2 & 3 & 3 \\
\hline 1 -Incline $(\geq 10 \%$ grade $)$ & 2 & 2 & 3 & 3 & 4 \\
\hline
\end{tabular}


Table 18.2 Cost of treating all roads in the city of Knoxville using the current method and the RVI method

\begin{tabular}{l|l|l|l|l|l}
\hline Approach & $\begin{array}{l}\text { Treatment } \\
\text { option }\end{array}$ & $\begin{array}{l}\text { Lane } \\
\text { miles }\end{array}$ & $\begin{array}{l}\text { Road-treatment } \\
\text { gauge }\end{array}$ & $\begin{array}{l}\text { Treatment cost } \\
\text { per lane mile }\end{array}$ & $\begin{array}{l}\text { Total cost for } \\
\text { treatment }\end{array}$ \\
\hline $\begin{array}{l}\text { Current } \\
\text { approach }\end{array}$ & All roads & 6555 & Full treatment & $\$ 49.80$ & $\$ 326,415$ \\
\hline $\begin{array}{l}\text { Proposed } \\
\text { approach }\end{array}$ & $\begin{array}{l}\text { Vulnerable } \\
\text { roads }\end{array}$ & 722 & $\begin{array}{l}25 \% \text { of full } \\
\text { treatment }\end{array}$ & $\$ 12.45$ & $\$ 8989$ \\
\cline { 2 - 6 } & $\begin{array}{l}\text { More } \\
\text { vulnerable } \\
\text { roads }\end{array}$ & 4916 & $\begin{array}{l}50 \% \text { of full } \\
\text { treatment }\end{array}$ & $\$ 24.90$ & $\$ 122,402$ \\
\cline { 2 - 6 } & $\begin{array}{l}\text { Most } \\
\text { vulnerable } \\
\text { roads }\end{array}$ & 917 & Full treatment & $\$ 49.80$ & $\$ 45,655$ \\
\cline { 2 - 6 } & All roads & 6555 & & & $\$ 177,046$ \\
\hline
\end{tabular}

should be given full treatment according to the current practice; Category 3 roads should remain safer with one-half of the full treatment; and Categories 1 and 2 roads should not need more than one-quarter of the full treatment to remain motorable. The simple cost analysis of Table 18.2 shows that using the RVI approach will not only reduce cost to about $54 \%$ of the total cost of treating all roads in the city using the current approach, but also will significantly decrease the amount of road salt used to achieve complete treatment (Fig. 18.5).

\subsection{Situational Awareness of National Energy Infrastructure}

The ability of the USA to effectively respond to and facilitate the restoration of energy infrastructures during disaster preparedness, response, and recovery depends on the ability of local, state, and federal government agencies, and private-sector electricity and fuel providers, to have access to timely, accurate, and actionable information about the status and potential impacts of energy-sector disruptions. Among the many critical requirements for decision support, two important challenges arise in (i) effective spatiotemporal representation of dynamic data and (ii) efficient integration of such data from disparate and distributed sources. This capability is currently provided by the U.S. Department of Energy (DOE) via its Environment for Analysis of Geo-Located Energy Information (EAGLE- ${ }^{\mathrm{TM}}$ ) system that is developed and maintained at ORNL. EAGLE-I ${ }^{\mathrm{TM}}$ and associated energy-infrastructure awareness capabilities provides an energy-sector-specific wide-area visualization and serves as the authoritative federal source for historical and real-time situational awareness for the nation's energy infrastructure through the National Outage Map (NOM), which shows the number of customers without electricity for every county in the USA. 




Fig. 18.5 RVI categories for each $50 \mathrm{~m}$ road segments in the city of Knoxville

Most utility companies provide customer outage status information covering their service regions via their websites. Having an integrated view of outage status across the nation is crucial for subject matter experts; but it is a challenging task because of data-source variations and changes, since utility companies may change the URLs of their outage information data sources and data formats. They may also support various data granularities such as latitude and longitude, county, zip code, city, census area, etc., they may change service areas, and they may need to handle too many utility companies. EAGLE-I ${ }^{\mathrm{TM}}$ provides an integrated, NOM system that has been systematically designed and developed. It is composed of several Python scripts that scrape data from utility company websites, standardize and store collected information into database tables, and track erroneous scripts. This capability incorporates the most current and relevant data, to provide effective and comprehensive support for energy-infrastructure awareness and response capabilities (Fig. 18.6).

Timely detection of electricity outage and restoration is a critical component of situational awareness during disruptive events for utility companies and emergency responders. Restoration is often slow because of significant delays in gathering efficient power-outage information and problems in allocating limited power resources. Crowdsourced data from social-media platforms are an attractive source to assess electricity outage in near-real time. Recent research by Mao et al. (2018) provided a 


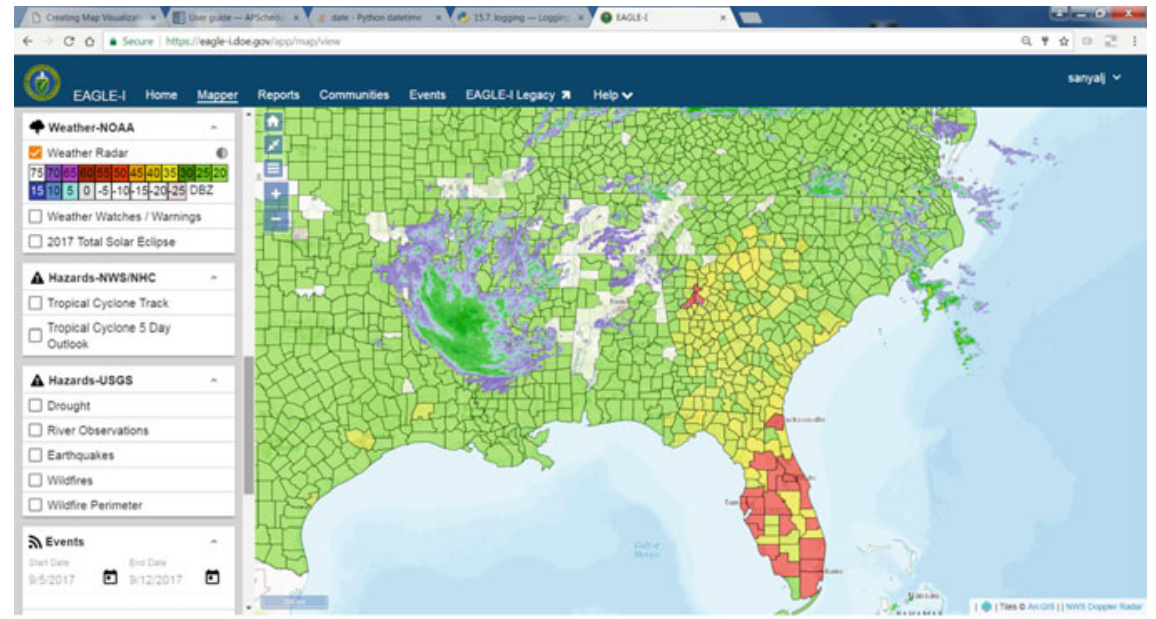

Fig. 18.6 Eagle- $\mathrm{I}^{\mathrm{TM}}$ displaying locations of over 7 million customers who lost electricity as an aftermath of Hurricane Irma in the southeastern USA during September 2017

novel two-stage framework based on machine learning and deep learning for poweroutage detection from Twitter. First, a probabilistic classification model was applied to find true power-outage tweets. Subsequently, a new deep-learning method (bidirectional long short-term memory networks) was implemented to extract outage locations from text. Results showed a promising classification accuracy (86\%) in identifying true power-outage tweets, and approximately 20 times more usable tweets can be located compared with simply relying on geotagged tweets.

\subsection{Conclusion}

As cities continue to grow and create more demand for resources, it is imperative that scientists and policymakers alike embrace and leverage the power of data science. This chapter discussed ways in which researchers at the U.S. Department of Energy's Oak Ridge National Laboratory are leveraging geographic data at scale to explore the population and land-use characteristics of cities in order to better inform urban issues such sustainability, particularly as it pertains to energy accessibility and consumption. The example of developing a synthetic population to estimate residential energy consumption at the household level demonstrates a generalizable method to fill existing data gaps in order to better understand and evaluate patterns of energy use. This is a useful approach for the USA and potentially other areas of the developed world where good-quality public-use microdata and complementary census summary tables exist. Where even those data are scarce, for example, in much of the developing world, other new approaches are needed. Using machinelearning algorithms to extract human-settlement areas from fine-resolution imagery 
and then correlating the results with nighttime lights data presents an example of this. The approach is scalable and provides an understanding of electricity consumption in urban areas where no ground data are available. Further, discerning types of human settlement can aid efforts to understand where underserved populations live and target these areas to improve access to basic services. Finally, it is important to make the connection between the science and how it can be used to make a positive impact for people and their environment. The example of a topological analysis of slums to increase the accessibility to services in urban areas is but one. An interdisciplinary approach to integrate foundational R\&D, operational communities, and industry is critical for the future success of UDI. By collaborating with public- and private-sector partners, researchers can connect foundational research and development, the operational community, and industry. While urbanization magnifies our current challenges of energy sustainability, resilience, and efficiency, it also provides a unique science and technology opportunity to learn from the past, bend the present, and shape the future of urban systems where our energy, environment, and mobility goals are collectively achieved.

Acknowledgements This manuscript has been authored by UT-Battelle, LLC under Contract DE-AC05-00OR22725 with the U.S. Department of Energy. The US Government retains and the publisher, by accepting the article for publication, acknowledges that the US Government retains a non-exclusive, paid-up, irrevocable, worldwide license to publish or reproduce the published form of this manuscript, or allow others to do so, for US Government purposes. The Department of Energy will provide public access to these results of federally sponsored research in accordance with the DOE Public Access Plan. The authors would like to acknowledge the funding support from US Government agencies and the Bill and Melinda Gates Foundation for the research discussed here. Sincere thanks to Dalton Lunga, Pranab Roy Choudhury, Husain Aziz, and Chris DeRolph for their help with some of the figures used here. Tremendous assistance from Ava Ianni in the manuscript preparation process is greatly appreciated and acknowledged.

\section{References}

Allen TFH, Star TB (2017) Hierarchy: perspectives for ecological complexity, 2nd edn. The University of Chicago Press, Chicago

Allen MR, Zaidi SMA, Chandola V, Morton AM, Brelsford CM, McManamay RA, Binita KC, Sanyal J, Stewart RN, Bhaduri BL (2018) A survey of analytical methods for inclusion in a new energy-water nexus knowledge discovery framework. Big Earth Data 2(3):197-227

Arndt J, Lunga D, Weaver J, Ledoux, ST Tennille S (2019) Multiscale based characterization and classification of urban land-use. In: 2019 IEEE international geoscience and remote sensing symposium (IGARSS). Yokohama, Japan, pp 9470-9473

Aziz HM, Park B, Morton A, Stewart RN, Hilliard M, Maness M (2018a) A high resolution agentbased model to support walk-bicycle infrastructure investment decisions: a case study with New York City Transportation. Transp Res Part C: Emerg Technol 86:280-299

Aziz HM, Nagle N, Morton A, Hilliard MR, White DA, Stewart RN (2018b) Exploring the impact of walk-bike infrastructure, safety perception, and built-environment on active transportation mode choice: a random parameter model using New York City commuter data. Transportation 45:1207-1229 
Bernhardt ES, Palmer MA, Allan JD, Alexander G, Barnas K, Brooks S, Carr J, Clayton S, Dahm C, Follstad-Smith J, Galat D, Glass S, Goodwin P, Hart D, Hassett B, Jenkinson R, Katz S, Kondolf GM, Lake PS, Lave R, Meyer JL, O’Donnell TK, Pagano L, Sudduth E (2005) Synthesizing U.S. river restoration efforts. Science 308:636-637

Bernhardt ES, Sudduth KB, Palmer MA, Allan JD, Meyer JL, Alexander G, Follastad-Shah J, Hassett B, Jenkinson R, Lave R, Rumps J, Pagano L (2007) Restoring rivers one reach at a time: results from a survey of U.S. river restoration practitioners. Restor Ecol 15:482-493

Bhaduri B, Bright E, Coleman P, Dobson J (2002) LandScan: locating people is what matters. Geoinformatics 5(2):34-37

Bhaduri B, Bright E, Coleman P, Urban ML (2007) LandScan USA: A high-resolution geospatial and temporal modeling approach for population distribution and dynamics. Geo J 69:103-117

Bhaduri B, Simon AJ, Allen MR, Sanyal J, Stewart RN, McManamay RA (2018) Energy-water nexus knowledge discovery framework, experts' meeting. Oak Ridge National Laboratory. ORNL/TM-2017/753. Jan 2018. https://doi.org/10.2172/1426570

Bigazzi AY, Bertini RL (2009) Adding green performance metrics to a transportation data archive. Transp Res Rec 2121(1):30-40

Black J, Arkin D (2014) Pinched: Salt shortage leads to dangerously slippery streets. NBC News [Online]. Available: http://www.nbcnews.com/storyline/deep-freeze/pinched-saltshortage-leads-dangerously-slippery-streets-n22516

Bradbury K, Saboo R, Johnson TL, Malof JM, Devarajan A, Zhang W, Collins LM, Newell RG (2016) Distributed solar photovoltaic array location and extent dataset for remote sensing object identification. Sci Data 3:160106. https://doi.org/10.1038/sdata.2016.106

Brelsford C, Martin T, Hand J, Bettencourt LM (2018) Toward cities without slums: Topology and the spatial evolution of neighborhoods. Sci Adv 4(8):eaar4644. https://doi.org/10.1126/sciadv. aar4644

Brewer SK, Worthington TA, Mollenhauer R, Stewart DR, McManamay RA, Guertault L, Moore D (2018) Synthesizing models useful for ecohydrology and ecohydraulic approaches: An emphasis on integrating models to address complex research questions. Ecohydrology. https://doi.org/10. 1002/eco.1966

Chapin F, Omitaomu OA, Bhaduri BL (2017) Making roads safer: Optimizing de-icing using snowmelt rates and slope data. In: Proceedings of the 2nd World Congress on Civil, Structural, and Environmental Engineering (CSEE'17), Barcelona, Spain, April 2-4

Chapman L, Thornes JE (2011) What spatial resolution do we need for a route-based road weather decision support system? Theoret Appl Climatol 104(3-4):551-559

Chini CM, Stillwell AS (2018) The state of US urban water: data and the energy-water nexus. Water Resour Res 54(3):1796-1811

Chowdhury PK, Weaver JE, Weber EM, Lunga D, LeDoux STM, Rose AN, Bhaduri BL (2020) Electricity consumption patterns within cities: application of a data-driven settlement characterization method. Int J Digital Earth 13(1):119-135. https://doi.org/10.1080/17538947.2018.155 6355

DeRolph CR, McManamay RA, Morton AM, Nair SS (2019) City energysheds and their implications for renewable energy penetration. Nature Sustainability 2:412-420. https://doi.org/10.1038/ s41893-019-0271-9

Horizon Systems Corporation (2019) NHDPlus Version 2. http://www.horizon-systems.com/nhd plus/. Accessed 8 Mar 2019

Hou X, Wang B, Hu W, Yin L, Wu H (2019) SolarNet: A deep learning framework to map solar power plants in China from satellite imagery. ArXiv, abs/1912.03685

IEA (2016) World Energy Outlook 2016, IEA, Paris https://www.iea.org/reports/world-energy-out look-2016

Kelting DL, Laxson CL (2010) Review of effects and costs of road de-icing with recommendations for winter road management in the Adirondack Park. http://www.protectadks.org/wp-content/upl oads/2010/12/Road_Deicing-1.pdf. Accessed 5 Mar 2019 
Kodysh JB, Omitaomu OA, Bhaduri BL, Neish BS (2013) Methodology for estimating solar potential on multiple building rooftops for photovoltaic systems. Sustain Cities Soc 8:31-41

Kurte K, Sanyal J, Berres A, Lunga D, Coletti M, Yang HL, Graves D, Liebersohn B, Rose A (2019) Performance analysis and optimization for scalable deployment of deep learning models for country-scale settlement mapping on Titan supercomputer. Concurrency Computation: Pract Experience e5305. https://doi.org/10.1002/cpe.5305

Latif, ZA, Zaki, NA, Salleh, SA (2012) GIS-based estimation of rooftop solar photovoltaic potential using LiDAR. In: 2012 IEEE 8th international colloquium on signal processing and its applications. pp 388-392

Lunga D, Yang HL, Reith A, Weaver J, Yuan J, Bhaduri B (2018) Domain-adapted convolutional networks for satellite image classification: a large-scale interactive learning workflow. IEEE J Sel Topics Appl Earth Observations Remote Sens 11(3):962-977

Mao H, Thakur G, Sparks K, Sanyal J, Bhaduri B (2018) Mapping near-real-time power outages from social media. Int J Digital Earth 12(11):1285-1299

Mao H, Ahn Y, Bhaduri B, Thakur G (2017) Improving land use inference by factorizing mobile phone call activity matrix. J Land Sci 12(2-3):138-153. https://doi.org/10.1080/1747423x.2017. 1303546

McManamay RA, Surendran Nair S, DeRolph CR, Ruddell BL, Morton AM, Stewart RN, Troia M, Tran L, Kim H, Bhaduri BL (2017) US cities can manage national hydrology and biodiversity using local infrastructure policy. Proc Natl Acad Sci 114:9581-9586. https://doi.org/10.1073/ pnas. 1706201114

McManamay RA, Smith JG, Jett RT, Mathews TJ, Peterson MJ (2018) Identifying non-reference sites to guide restoration and long-term monitoring. Sci Total Environ 621:1208-1223. https:// doi.org/10.1016/j.scitotenv.2017.10.107

McManamay RA, DeRolph CR (2019a) A stream classification system for the conterminous United States. Sci Data 6:190017

McManamay RA, DeRolph CR (2019b) Stream classification Web app. https://hydrosource.ornl. gov/environmental-information/us-stream-classification-system

Moore A (2019) Optimization of intra-city freight movement with new delivery methods. In: 98th Annual Meeting of the Transportation Research Board, Washington DC

Morton A, Nagle N, Piburn J, Stewart RN, McManamay R (2017) A hybrid dasymetric and machine learning approach to high-resolution residential electricity consumption modeling, In: Advances in Geocomputation, Geocomputation 2015. Springer International Publishing, Berlin, pp 47-58

Morton A, Piburn J, Nagle N, Aziz HM, Duchscherer SE, Stewart RN (2017) A simulation approach for modeling high-resolution daytime commuter travel flows and distributions of worker subpopulations. Geocomputation 2017, Leeds UK, September

Nguyen HT, Pearce JM, Harrap R, Barber G (2012) The application of LiDAR to assessment of rooftop solar photovoltaic deployment potential in a municipal district unit. Sensors 12(4):45344558. https://doi.org/10.3390/s120404534

NRCS (2004) Part 630 Hydrology; Chapter 11-Snowmelt. National resources conservation service, United States Department of Agriculture

Park BH, Aziz HM, Morton A, Stewart R (2018) High performance data driven agent-based modeling framework for simulation of commute mode choices in metropolitan area. In: 21st IEEE international conference on intelligent transportation system, Hawaii

Rose AN, Nagle NN (2017) Validation of spatiodemographic estimates produced through data fusion of small area census records and household microdata. Comput Environ Urban Syst 63:38-49

Ruddell BL, Adams EA, Rushforth R, Tidwell VC (2014) Embedded resource accounting for coupled natural-human systems: An application to water resource impacts of the western U.S. electrical energy trade. Water Resour Res 50:7957-7972

Seeherman J, Liu Y (2015) Effects of extraordinary snowfall on traffic safety. Accid Anal Prev 81:194-203

Seto K, Dhakal S, Bigio A, Blanco H, Delgado GC, Dewar D, Huang L, Inaba A, Kansal A, Lwasa S, McMahon J, Müller D, Murakami J, Nagendra H, Ramaswami A (2014) Human settlements, 
infrastructure and spatial planning. In: Edenhofer O et al (eds) Climate change 2014: Mitigation of climate change. Contribution of Working Group III to the Fifth Assessment Report of the Intergovernmental Panel on Climate Change, IPCC, Geneva, pp 923-1000

Sierra Club (2018) https://www.sierraclub.org/sites/www.sierraclub.org/files/blog/1846\%20R F100-CaseStudies2018_Report_05_web.pdf

Transportation Research Board (1991) Highway deicing: Comparing salt and calcium magnesium acetate. Special Report 235. http://onlinepubs.trb.org/onlinepubs/sr/sr235/00i-012.pdf. Accessed 5 Mar 2019

UN Habitat (2016) Slum almanac 2015-2016: Tracking improvements in the lives of slum dwellers. United Nations Human Settlements Programme, Nairobi, Kenya. http://unhabitat.org/slum-alm anac-2015-2016/

USACE (1998) HEC-1 flood hydrograph package. Hydrological Engineering Center, Davis, CA

USDOE (2014) The water-energy nexus: Challenges and opportunities. US Department of Energy. Available at: https://www.energy.gov/downloads/water-energy-nexus-challenges-and-opportuni ties

US Energy Information Administration (2019) International Energy Outlook 2019 with projections to 2050. https://www.eia.gov/outlooks/ieo/pdf/ieo2019.pdf

USGS (2018) Water use in the United States. U.S. Geological Survey. https://water.usgs.gov/wat use/

Weber E, Seaman V, Stewart R, Bird TJ, Tatem AJ, McKee JJ, Bhaduri B, Moehl J, Reith AE (2018) Census-independent population mapping in Northern Nigeria. Remote Sens Environ 204:786798. https://doi.org/10.1016/j.rse.2017.09.024

World Health Organization (2019) Global Health Observatory (GHO) data. https://www.who.int/ gho/urban_health/situation_trends/urban_population_growth_text/en/

Yang HL, Yuan J, Lunga D, Laverdiere M, Rose A, Bhaduri B (2018) Building extraction at scale using convolutional neural network: Mapping of the United States. IEEE J Sel Topics Appl Earth Observations Remote Sens 11(8):2600-2614. https://doi.org/10.1109/jstars.2018.2835377

Yu J, Wang Z, Majumdar A, Rajagopal R (2018) DeepSolar: a machine learning framework to efficiently construct a solar deployment database in the United States. Joule 2:2605-2617. https:// doi.org/10.1016/j.joule.2018.11.021

Yuan J, Wang D, Cheriyadat AM (2015) Factorization-based texture segmentation. IEEE Trans Image Process 24(11):3488-3497

Yuan J, Yang H-H, Omitaomu OA, Bhaduri BL (2016) Large-scale solar panel mapping from aerial images using deep convolutional networks. In: IEEE international conference on big data. Washington, DC

Zaidi SMA, Chandola V, Allen MR, Sanyal J, Stewart RN, Bhaduri BL, McManamay RA (2018) Machine learning for the energy-water nexus: challenges and opportunities. Big Earth Data 2(3):228-267. https://doi.org/10.1080/20964471.2018.1526057 




Budhendra Bhaduri is a Division Director and Corporate Research Fellow at Oak Ridge National Laboratory and holds joint professorial appointments at the University of Tennessee, Knoxville. He is a fellow of the American Association for the Advancement of Science and interested in GIScience and technology applications across energy, environment, and national security missions.

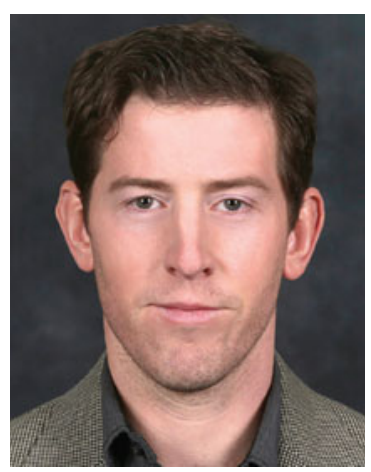

Ryan McManamay is an Assistant Professor within the Department of Environmental Science at Baylor University. His research examines human-environmental systems aimed at balancing ecosystem and societal needs, specifically the effects of macro-scale urban expansion with respect to changes in land cover, energy and water infrastructure, shifts in regional to global water budgets, and ultimate consequences to biodiversity.

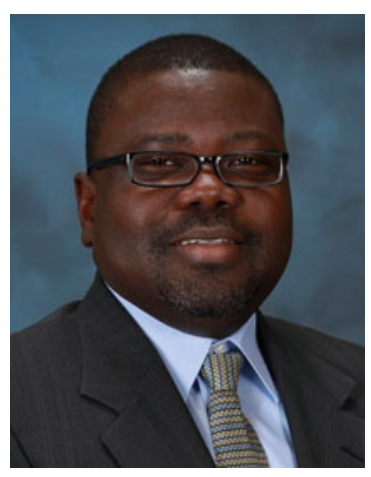

Olufemi Omitaomu is a Senior R\&D Staff member in Computational Systems Modeling at Oak Ridge National Laboratory (ORNL), and also a Joint Faculty Associate Professor in the Department of Industrial and Systems Engineering at the University of Tennessee, Knoxville. He is a Senior Member of IEEE and IISE. 


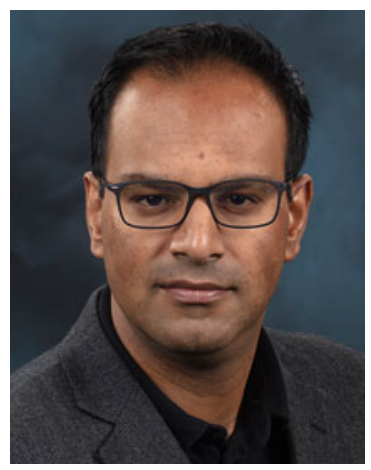

Jibo Sanyal is currently the group leader for the Computational Urban Sciences Group at Oak Ridge National Laboratory. He holds a Ph.D. in Computer Science from Mississippi State University from 2011. He is a member of ACM, AGU, IBPSA, and a Senior Member of IEEE.

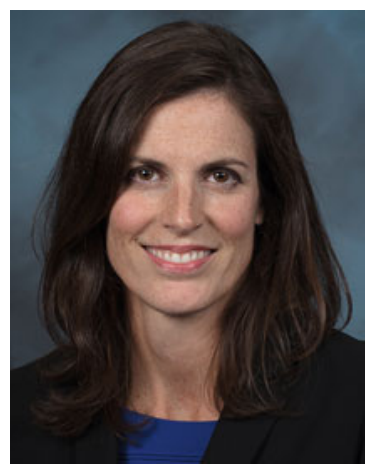

Amy Rose is a Senior R\&D Staff in Human Geography at Oak Ridge National Laboratory and serves as Joint Faculty Assistant Professor in the Department of Industrial and Systems Engineering at The University of Tennessee. Her interests are in geocomputational methods to characterize the spatiotemporal and demographic patterns of human populations.

Open Access This chapter is licensed under the terms of the Creative Commons Attribution 4.0 International License (http://creativecommons.org/licenses/by/4.0/), which permits use, sharing, adaptation, distribution and reproduction in any medium or format, as long as you give appropriate credit to the original author(s) and the source, provide a link to the Creative Commons license and indicate if changes were made.

The images or other third party material in this chapter are included in the chapter's Creative Commons license, unless indicated otherwise in a credit line to the material. If material is not included in the chapter's Creative Commons license and your intended use is not permitted by statutory regulation or exceeds the permitted use, you will need to obtain permission directly from the copyright holder.

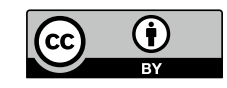

